\title{
Dielectric and electro-optic properties of cybotactic nematic phase in hydrogen-bonded liquid crystals
}

Tayssir Missaoui ${ }^{\mathrm{a}}$, Ines Ben Amor ${ }^{\mathrm{b}}$, Taoufik Soltani ${ }^{\mathrm{b}}$, Hafedh Ben Ouada ${ }^{\mathrm{a}}$, Erwann Jeanneau ${ }^{\mathrm{c}}$, Yves Chevalier ${ }^{\mathrm{d}}$

${ }^{a}$ Université de Monastir, Faculté des Sciences de Monastir, Laboratoire des Interfaces et Matériaux Avancés, bd de l'Environnement, 5019 Monastir, Tunisia.

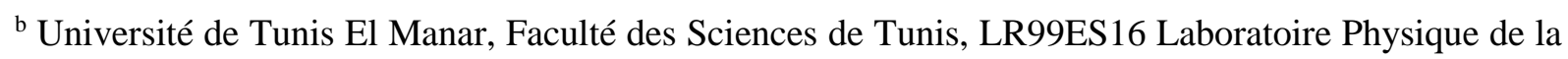
Matière Molle et de la Modélisation Électromagnétique, 2092 Tunis, Tunisia.

c Université Claude Bernard Lyon 1, Centre de Diffractométrie Henri Longchambon, 69622 Villeurbanne, France.

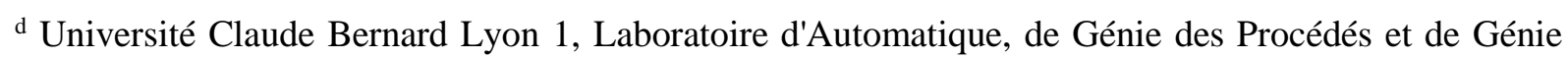
Pharmaceutique, LAGEPP, CNRS UMR 5007, 43 bd 11 Novembre, 69622 Villeurbanne Cedex, France.

Corresponding authors:

- Yves Chevalier, Université Claude Bernard Lyon 1, Laboratoire d'Automatique, de Génie des Procédés et de Génie Pharmaceutique, LAGEPP, CNRS UMR 5007, 43 bd 11 Novembre, 69622 Villeurbanne Cedex, France.+33 472431877, yves.chevalier@univ-lyon1.fr

- Taoufik Soltani, Université de Tunis El Manar, Faculté des Sciences de Tunis, LR99ES16 Laboratoire Physique de la Matière Molle et de la Modélisation Électromagnétique, 2092 Tunis, Tunisia. +216 21064017, tawfik_sol@yahoo.fr 


\begin{abstract}
The new compounds 4-decyloxy-2-fluorobenzoic acid and 4-dodecyloxy-2-fluorobenzoic acid display hydrogen-bonded liquid crystals (HBLC) of smectic and nematic phases. Their phase behavior established using polarizing optical microscopy (POM), differential scanning calorimetry (DSC) and X-ray diffraction (XRD) consistently occurs as the sequence upon cooling: Isotropic liquid - Nematic - SmC - crystalline solid. The dielectric study in the nematic phase shows a single relaxation process at low frequency characteristic of a cybotactic nematic phase. The optical properties of the nematic phase show a decrease of birefringence as alkyl chain length increases in the high-temperature part of the nematic domain, which reveals a decrease of order parameter for longer chains.
\end{abstract}

Keywords: Hydrogen-bonded liquid crystal, Nematic, Polarized optical microscopy, Dielectric spectroscopy.

\title{
Highlights:
}

- 4-Alkyloxy-2-fluorobenzoic acids self-associate as hydrogen-bonded SmC and nematic liquid crystals

- The decyl and dodecyl compounds form cybotactic nematic phases

- The nematic phase shows spontaneous polarization and low frequency relaxation at $8 \mathrm{kHz}$ 


\section{Introduction}

Hydrogen-bonded liquid crystals (HBLC) make a specific class of thermotropic liquid crystals formally introduced by Kato and Fréchet in 1989 [1]. The building blocks are hydrogen-bonded complex species of molecules that their free form may not self-associate as liquid crystals. There have been many previous reports of HBLC though this terminology was not used at that time [2-8]; even in some instances it was not recognized that hydrogen bonds were involved for the formation of liquid crystals. Much attention is paid to HBLC due to their specific properties for both fundamental aspects and various technological applications. Thermotropic liquid crystals exhibit different phases between the isotropic liquid at high temperature and the solid crystalline phase at low temperature [9]; HBLC show the same variety of structures. The most well-known LC mesophase is the nematic phase, where anisotropicshaped molecules exhibit short-range orientational order, defined by a local vector (the director).

Aromatic carboxylic acids were often utilized in the preparation of HBLC's. Most of HBLC mesogens are made of symmetric dimers of molecules showing nematic and smectic phases [26,10-13]. The investigation of several aromatic carboxylic acids and their mixtures has been continued by Pongali Sathya Prabu et al. [12] and by Fouzai et al. [13] who found that small structural modification significantly changed the phase behavior. On the other hand, the heteroassociation of compounds by intermolecular hydrogen-bonding between a basic (e.g. pyridine derivative) and an acidic (e.g. alkoxybenzoic acid) form liquid crystalline phases showing a rich polymorphism such as $\mathrm{SmC}, \mathrm{SmA}, \mathrm{SmF}, \mathrm{SmG}, \mathrm{SmI}$, nematic, discotic... phases based on the proton donor and acceptor interactions [1,14-22]. Ferroelectric HBLC materials were obtained by hydrogen-bonding hetero-association of chiral molecules [23-28].

Such large variety of molecular structures able to form, in particular asymmetric molecules show up specific behavior that may reveal the presence of unexpected and anomalous properties $[5,6,13,29,30]$. As example, a cybotactic nematic phase due to the presence of ferroelectric clusters has been observed [29]. More surprisingly, recent work on fluorinated HBLC by our group have also revealed the appearance of a low frequency relaxation (about $7 \mathrm{kHz}$ ) in the nematic phase [13]. This mode has been ascribed to presence of the ferroelectric clusters and electro-optic measurements clearly indicated the formation of a cybotactic nematic phase [30]. The reason of its formation is still unknown and some aspects remain to be explored.

Dielectric spectroscopy is quite a suitable method for liquid crystal characterization. It allows the study of dielectric properties of materials, but also the determination of phase transition temperatures and the identification of phases. 
In this paper we examine the dielectric and electro-optic measurements in the cybotactic nematic phase of fluorinated HBLC's of varying alkyl chain length $(n=8,10$ and 12$)$ in order to better understand the formation of cybotactic nematic phases. In addition, increasing the length of the alkyl chain in this series of fluorinated compounds allowed studying its influence on the phase sequence and liquid crystalline properties. In this paper, we report the synthesis and the characterization of two new compounds, 4-decyloxy-2-fluorobenzoic acid (10OBAF) and 4-dodecyloxy-2-fluorobenzoic acid (12OBAF), which could be used for several applications such as photonics and plasmonics [31]. The molecular structure of these compounds is shown in Fig. 1.

\section{Experimental}

\subsection{Synthesis and structural analysis}

4-Decyloxy-2-fluorobenzoic acid (10OBAF) and 4-dodecyloxy-2-fluorobenzoic acid (12OBAF) are two pure HBLCs synthesized in our laboratory by the method described in [13]. The chemical structure of the products was characterized by IR and NMR spectroscopy. Fourier transform infrared spectra were recorded on dry powders in Attenuated Total Reflectance mode (FTIR-ATR) using a Nicolet ${ }^{\mathrm{TM}}$ iS50 FT-IR spectrometer. Spectra were recorded in the range $500-4000 \mathrm{~cm}^{-1}$ at a resolution of $4 \mathrm{~cm}^{-1}$ and using 32 scans for each spectrum. They are displayed in absorption mode. ${ }^{1} \mathrm{H},{ }^{13} \mathrm{C}$ and non-decoupled ${ }^{19} \mathrm{~F}$ NMR spectra were run on a Bruker AV $300 \mathrm{MHz}$ spectrometer. All spectra were recorded using $\mathrm{CDCl}_{3}$ as solvent. Chemical shifts of ${ }^{1} \mathrm{H}$ and ${ }^{13} \mathrm{C}$ NMR spectra are reported in ppm from TMS. Chemical shifts of ${ }^{19} \mathrm{~F}{ }^{1} \mathrm{NMR}$ spectra are reported in ppm from $\mathrm{CFCl}_{3}$.

\subsubsection{NMR analysis}

4-Decyloxy-2-fluorobenzoic acid (10OBAF): White powder. ${ }^{1} \mathrm{H}$ NMR $\left(300 \mathrm{MHz}, \mathrm{CDCl}_{3}\right)$, $\delta$ (ppm): 0.80 (t, 3H, $\mathrm{CH}_{3}$ of $\left.\mathrm{C}_{10} \mathrm{H}_{21}\right), 1.20-1.38$ (m, 14H, $7 \mathrm{CH}_{2}$ of $\left.\mathrm{CH}_{3}-\left(\mathrm{CH}_{2}\right)_{7}-\right), 1.7-1.8(\mathrm{~m}$, $\left.2 \mathrm{H}, \beta \mathrm{CH}_{2}-\mathrm{CH}_{2}-\mathrm{O}\right), 4.0\left(\mathrm{~m}, 2 \mathrm{H}, \mathrm{CH}_{2}-\mathrm{O}\right), 6.75$ (m, $2 \mathrm{H}$ arom., ortho and para to $\mathrm{F}$ ), 8.0 (m, $1 \mathrm{H}$ arom., meta to $\mathrm{F}) .{ }^{13} \mathrm{C} \mathrm{NMR}\left(101 \mathrm{MHz}, \mathrm{CDCl}_{3}\right)$ 169.23, 165.55, 165.01, 162.95235, 134.02, $110.81,109.49,102.89,102.63,68.81,31.89,29.31,28.92,25.91,22.68,14.12 .{ }^{19} \mathrm{~F} \mathrm{NMR}$ $\left(282 \mathrm{MHz}, \mathrm{CDCl}_{3}\right)-105.429 \mathrm{ppm}\left(\mathrm{dd},{ }^{3} \mathrm{~J}_{\mathrm{F}-\mathrm{H}}=12.68 \mathrm{~Hz},{ }^{3} \mathrm{~J}_{\mathrm{F}-\mathrm{H}}=8.65 \mathrm{~Hz}\right)$.

4-Dodecyloxy-2-fluorobenzoic acid (12OBAF): White powder. ${ }^{1} \mathrm{H}$ NMR $(300 \mathrm{MHz}$, $\left.\mathrm{CDCl}_{3}\right), \delta$ (ppm): 0.80 (t, 3H, $\mathrm{CH}_{3}$ of $\left.\mathrm{C}_{8} \mathrm{H}_{17}\right), 1.20-1.36$ (m, $16 \mathrm{H}, 8 \mathrm{CH}_{2}$ of $\left.\mathrm{CH}_{3}-\left(\mathrm{CH}_{2}\right)_{8}-\right), 1.5-$ 1.8 (m, 2H, $\mathrm{\beta CH}_{2}-\mathrm{CH}_{2}-\mathrm{O}$ ), 1.8 (m, 2H, $\alpha \mathrm{CH}_{2}-\mathrm{O}$ ), 3.9 (m, 2H, $\mathrm{CH}_{2}-\mathrm{O}$ ), 6.75 (m, 2H arom., ortho and para to F), 8.0 (m, $1 \mathrm{H}$ arom., meta to F). ${ }^{13} \mathrm{C} \mathrm{NMR}\left(101 \mathrm{MHz}, \mathrm{CDCl}_{3}\right)$ 169.51, 165.57, $165.03,162.97,134.05,134.03,110.77,109.43$, 102.89, 102.64, 68.81, 31.92, 29.64, 29.36, 
28.92, 25.91, 22.70, 14.12. ${ }^{19} \mathrm{~F}$ NMR (282 MHz, $\left.\mathrm{CDCl}_{3}\right)$ : $-105.456 \mathrm{ppm}\left(\mathrm{dd},{ }^{3} \mathrm{~J}_{\mathrm{F}-\mathrm{H}}=12.83 \mathrm{~Hz}\right.$, $\left.{ }^{3} \mathrm{~J}_{\mathrm{F}-\mathrm{H}}=8.50 \mathrm{~Hz}\right)$.

\subsubsection{IR analysis}

IR spectra of 10OBAF and 12OBAF showed the same features (Fig. 2): a broad band at $2700-3300 \mathrm{~cm}^{-1}$ assigned to $v(\mathrm{O}-\mathrm{H})$ mode of carboxylic acid group, a sharp band at $1691 \mathrm{~cm}^{-1}$ from $v(\mathrm{C}=\mathrm{O})$ mode and three sharp bands at 1615,1509 and $1469 \mathrm{~cm}^{-1}$ from $v(\mathrm{C}=\mathrm{C})$ of aromatic system. Moreover, the band occurring at $1293 \mathrm{~cm}^{-1}$ corresponds to $\mathrm{C}-\mathrm{F}$ stretching vibrations. The sharp band of carbonyl at $1691 \mathrm{~cm}^{-1}$ confirmed the dimeric association of alkyloxybenzoic acids in the crystalline phase at room temperature. Indeed, a carboxylic acid existing in monomeric form in dilute solution absorbs at about $1760 \mathrm{~cm}^{-1}$. It should be noted that several sharp bands of carbonyl corresponding to cyclic $\left(1680 \mathrm{~cm}^{-1}\right)$, open dimers $\left(1700 \mathrm{~cm}^{-1}\right)$ and monomeric species $\left(1620 \mathrm{~cm}^{-1}\right)$ in dynamic equilibrium have been observed in POBA by Martínez-Felipe et al. [32]. A single sharp band of the cyclic dimer at $1691 \mathrm{~cm}^{-1}$ was observed in the present case, suggesting that the presence of a fluorine atom favors the cyclic dimers.

\subsection{Measurement set-up and instruments}

Differential scanning calorimetry (DSC) using a Perkin-Elmer DSC7 was performed at heating and cooling rates were $5^{\circ} \mathrm{C} \cdot \mathrm{min}^{-1}$. Texture and their changes were observed using an Olympus BX51 polarizing optical microscope (POM) equipped with digital CCD camera (Sony).

X-ray diffraction (XRD) studies were performed using a Gemini diffractometer with graphite-monochromatized MoK $\alpha$ radiation at $\lambda=0.71073 \AA$. It was equipped with a Gemini CCD detector. Data reduction was done using the Crysalis Pro software. Intensities were collected at several temperatures.

Dielectric and optical properties were studied using commercial planar alignment cells to evaluate threshold voltage and birefringence. Commercial cells (EHC from Japan) coated with ITO (indium tin oxide), and rubbed polyimide were used. The cells thickness defined by Mylar sheets was $8 \mu \mathrm{m}$, and the active area was $0.25 \mathrm{~cm}^{2}$. The cell was filled with the studied compounds in the isotropic phase by capillary action and slowly cooled into the nematic phase. The temperature was controlled within $\pm 1^{\circ} \mathrm{C} \cdot \mathrm{min}^{-1}$.

The real and imaginary parts of the complex permittivity $\left(\varepsilon=\varepsilon^{\prime}-\mathrm{i} \varepsilon^{\prime \prime}\right)$ were measured with an impedance-meter in the frequency range of $10 \mathrm{~Hz}-200 \mathrm{kHz}$. At the same time a sinusoidal voltage modulation of $500 \mathrm{mVp}$ was applied. The threshold voltage measurements were carried 
out as a function of temperature by connecting the sample to a generator coupled with an amplifier which can provide voltages between $0.5 \mathrm{~V}$ and $50 \mathrm{~V}$. An arbitrary square wave (10 V and $1 \mathrm{~Hz}$ ) was applied to the cell. Spontaneous polarization was measured by integrating the switching current recorded during polarization reversal under applied triangular voltage with frequency of $30 \mathrm{~Hz}$.

Birefringence was measured through the phase retardation of the sample $(\delta)$ using the prism method [30], in which the sample was placed between two crossed linear polarizers with a rubbing direction at $45^{\circ}$ to their extinction directions under polychromatic light beam of average wavelength $546 \mathrm{~nm}$. Birefringence $(\Delta n)$ was measured at several temperatures.

\section{Results}

The phase behavior of 10OBAF and 12OBAF was assessed by DSC and POM observations as a function of temperature.

For both 10OBAF and 12OBAF, DSC measurements showed three well-defined endothermal peaks on heating and three exothermic peaks on cooling indicating the existence of four phases (Fig. 3). The texture observed by optical microscopy confirmed these results. Indeed, on cooling from the isotropic liquid, planar textures of the nematic phase first appeared (Fig. 4a). On further cooling, the smectic phase ( $\mathrm{SmC}$ ) arose as given evidence by its typical texture (Fig. 4b).

The SmC-nematic and nematic-isotropic transition temperatures were almost the same upon heating and cooling. Conversely, the temperature for crystallization was much lower upon cooling than heating, which is quite a general phenomenon for crystallization of bulk materials from their melt. The thermodynamic melting temperature was that measured upon heating. Table 1 summarizes the domains of existence of the different phases from the present study of 10OBAF and 12OBAF, together with data of $8 \mathrm{OBAF}$ from previous work [30]. Both techniques of DSC and POM revealed an increase of melting temperature and a decrease of the nematicisotropic transition with respect to the length of the alkyl chain. As a whole, the temperature range of mesophases increases upon shortening the alkyl chain length.

The structure of mesophases was investigated by XRD. The 2D XRD of the different phases of 10OBAF and 12OBAF liquid crystals are shown in Fig. 5. The natures of these phases were assigned following reference [33]. Starting from the highest temperature, an isotropic liquid phase was characterized by an isotropic wide-angle diffuse scattering as a Debye-Scherrer ring characteristic of a classical liquid. A nematic liquid crystalline phase was observed upon cooling. It was characterized by an anisotropic diffraction pattern showing an orientational 
order. A wide-angle diffuse scattering was observed, showing that there was no periodic positional order. These features are those of a nematic structure. A strong diffuse scattering was detected in the direction perpendicular to the wall of the capillary sample holder, showing that the director of the nematic phase was parallel to the wall of the container. Upon cooling again, the smectic phase was entered. It was characterized by an anisotropic pattern with diffuse scattering in the wide-angle range. The smectic structure is made of a periodic arrangement of molecular layers in the direction of the director. The director is presumed parallel to the wall of the sample holder as it was in the nematic phase. The wide-angle scattering was tilted with respect to the direction perpendicular to the director, showing that molecules were tilted and that the smectic phase is of SmC type. Its period is of the order of twice the molecular size along its long axis. Such long period yields Bragg reflections in the small-angle range that could not be observed in the present case because the experimental setup could not reach a low enough angular domain. A detailed structural study could not be achieved because of this lack of information in the small-angle range. Polarized optical microscopy has unambiguously shown that this phase was of smectic structure. The solid crystalline phase was reached upon cooling again. Its scattering pattern was made of Bragg reflections, showing the 3D positional order of molecules in such crystals. The diffraction pattern was close to that of a single crystal because the size of crystals grown upon cooling was quite large with respect to the cross-section of the $\mathrm{X}$-ray beam. The structures of these phases were in agreement with the POM observations.

The broad diffuse scattering pattern observed in the wide-angle region of the nematic phase corresponds to scattering derived from main lateral intermolecular distance $\left(d_{\mathrm{waxs}}\right)$. The value of $d_{\text {waxs }}$ calculated from the Bragg relationship varied from $4.55 \AA$ at $110^{\circ} \mathrm{C}$ to $4.50 \AA$ at $102^{\circ} \mathrm{C}$ for $12 \mathrm{OBAF}$ and from $4.50 \AA$ to $4.48 \AA$ for 10OBAF. Similar behavior was observed in HBLC with alkylthio groups [29].

The dielectric anisotropy, dispersion, relaxation phenomena and loss tangent characteristics of the dielectric behavior of liquid crystals have been determined by fitting the Cole-Davidson distribution of relaxation times (Eq 1) to the real $\varepsilon$ ' and imaginary $\varepsilon$ " parts of the complex dielectric permittivity [30,33]:

$$
\varepsilon^{*}=\varepsilon_{\infty}+\frac{\Delta \varepsilon}{\left(1+(i \omega \tau)^{\alpha}\right)}
$$

where $\omega$ is the angular frequency, $\varepsilon_{\infty}$ is the high-frequency dielectric constant, $\tau=1 / 2 \pi f_{\mathrm{R}}\left(f_{\mathrm{R}}\right.$ is the relaxation frequency) is the relaxation time, $\Delta \varepsilon=\varepsilon_{0}-\varepsilon_{\infty}$ is the dielectric increment (strength) and $\alpha$ is the Cole-Davidson distribution parameter. 
The complex dielectric constant $\left(\varepsilon^{*}=\varepsilon^{\prime}-\mathrm{i} \varepsilon^{\prime \prime}\right)$ was measured either at a constant frequency during continuously cooling the sample or at stabilized temperature by varying the frequency from $100 \mathrm{~Hz}$ to $13 \mathrm{MHz}$ upon applying a constant bias field. The frequency dependence of the real $\left(\varepsilon^{\prime}\right)$, and imaginary $\left(\varepsilon^{\prime \prime}\right)$ parts of the dielectric constant, in nematic phase of 10OBAF are given in Figs $6 \mathrm{a}$ and $6 \mathrm{~b}$, respectively. The single relaxation observed at low frequency $(\approx 8 \mathrm{kHz})$ was attributed to the rotation of molecules around their short molecular axis. This relaxation peak decreased in magnitude and slightly shifted to higher frequencies upon increasing temperature. The latter result is consistent with the electro-optic behavior (described later) as the magnitude of this mode is related to the spontaneous polarization. It is worth to notice that the relaxation mode at low frequency has been observed in the 8OBAF [13], and in other HBLC's [12] over the entire nematic range. This mode is a characteristic property of the presence of polar domains indicating the formation of a cybotactic nematic phase.

Fig. 7 presents the temperature dependence of the imaginary permittivity ( $\left.\varepsilon^{\prime \prime}\right)$ of 10OBAF at $2 \mathrm{kHz}$, which shows significant changes at $114^{\circ} \mathrm{C}$ and $76^{\circ} \mathrm{C}$ indicating the $\mathrm{I}-\mathrm{N}$ and SmC - Crystal phase transitions, respectively. This result is in good agreement with DSC measurements. A plot of $\log \left(f_{\mathrm{r}}\right)$ with respect to the inverse temperature exhibited an Arrheniustype behavior (Eq 2) as shown in Fig. 8.

$$
f_{r}=f_{0} e^{\left(\frac{-E_{a}}{k_{B} T}\right)}
$$

The activation energy obtained from the slope was $E_{\mathrm{a}}=0.9 \mathrm{eV}$ for $10 \mathrm{OBAF}$. Similar observations were made in the nematic phase of 12OBAF. This value is of the same order of magnitude but higher than $\sim 0.35 \mathrm{eV}$ for 8OBA and 8OBAF [30] and lower than $3.6 \mathrm{eV}$ measured in a similar HBLC [34].

The low frequency relaxation in the nematic phase can be explained by the existence of ferroelectric clusters. In order to get support to this idea, the spontaneous polarization $(P s)$ has been measured for all three compounds. As pictured in Fig. 9, the temperature dependence of $P$ s showed an unusual behavior at low temperature in the nematic phase of 10OBAF. Indeed, the value of $P$ s for this compound increased upon cooling and decreased suddenly as the $\mathrm{N}-\mathrm{SmC}$ transition was passed through. Such reversal of the temperature dependence has not been observed for 8OBAF [30]. It has already been detected in some achiral bent-core liquid crystals and has been explained by an increasing size of ferroelectric clusters [33]. In this later case, a polarization has also been detected in a narrow temperature range in the isotopic phase indicating the persistence of clusters in the isotropic phase. However in the present case, polarization could only be detected in the nematic phase. The value of Ps for 12OBAF was 
much smaller and no significant change was observed. The increase of amplitude of the lower frequency mode upon decreasing temperature can be explained by the increase of $P$ s because both quantities are proportional.

The threshold electric field $\left(E_{\mathrm{th}}\right)$ is one of the important parameters of the nematic phase. It is related to the length of liquid crystalline molecules and plays an important role from the application point of view. Fig. 10 presents the temperature dependence of $E_{\text {th }}$ for the three compounds: the previously reported 8OBAF [13], 10OBAF, and 12OBAF in the nematic phase. $E_{\text {th }}$ increased with decreasing temperature, which is the typical behavior caused by the higher viscosity at lower temperatures. In addition, its value decreased with increasing the chain length. For example, at $T=100^{\circ} \mathrm{C}, E_{\text {th }}=1.07 \mathrm{~V} \cdot \mu \mathrm{m}^{-1}$ for $8 \mathrm{OBAF}, E_{\mathrm{th}}=0.66 \mathrm{~V} \cdot \mu \mathrm{m}^{-1}$ for $10 \mathrm{OBAF}$ and $E_{\mathrm{th}}=0.47 \mathrm{~V} \cdot \mu \mathrm{m}^{-1}$ for $12 \mathrm{OBAF}$. These values are comparable to those measured in $\mathrm{nCB}$ compounds, and much lower than values obtained with other HBLC's [21]. This may be attributed to the decreases of the order parameters $(S)$, based on the well-known proportionality $V_{\text {th }} \alpha \sqrt{S}$ [35]. As the chain length increases, the free volume increases leading to a reduction of the structure packing and parameter order.

The temperature dependence of the birefringence for the three compounds is given in Fig. 11. The birefringence slightly decreased with respect to temperature, which can be explained by the decreasing order parameter as temperature decreases. $\Delta n$ of $10 \mathrm{OBAF}$ reached a maximum value of 0.13 near the transition to the smectic phase. This value is significantly lower than that of the well-known 5CB compound [36].

The temperature dependence of $\Delta n$ near the $\mathrm{N}$ - I transition can be described by the following equation known as "Haller extrapolation" [37-40]:

$$
\Delta n=\Delta n_{0}\left(T_{C}-T\right)^{\beta}
$$

where $\beta$ is an exponent characteristic of the material, $\Delta n_{0}$ is the birefringence at $T=0 \mathrm{~K}$ and $T_{\mathrm{C}}$ is the transition temperature from isotropic to nematic phase. $\Delta n_{0}$ and $\beta$ were obtained from a fit of Eq. 3 to experimental data. This yielded: $\beta=0.106$ for 8OBAF, $\beta=0.15$ for 10OBAF, and $\beta=0.17$ for 12OBAF. The birefringence at $0 \mathrm{~K}$ was: $\Delta n_{0}=0.082$ for $8 \mathrm{OBAF}, \Delta n_{0}=0.074$ for 10OBAF, and $\Delta n_{0}=0.062$ for 12OBAF. For the 8OBAF compound, the birefringence was $\Delta n=0.17$ at $100^{\circ} \mathrm{C}$, which was higher than $\Delta n$ measured for $10 \mathrm{OBAF}(0.12)$, and for $12 \mathrm{OBAF}$ $(0.11)$ at the same temperature.

\section{Discussion and conclusion}


Fluoro-substitution of chiral LC [41], bent-core LC [33,42] and HBLC [43] bring about specific behavior which deserves investigation. Indeed, enhancements of viscoelastic, dielectric and optical properties have been reported in several instances. For example, reduced threshold and formation of SmF phase on heating have been observed for 8OBAF compared to the nonfluorinated homologue 8OBA [13]. Therefore, 10OBAF and 12OBAF were investigated with the expectation that the fluorine substituent could induce ordered SmF, SmB and/or SmG smectic phases. However, none of these phases was detected in the present case. Instead, the Crystal - SmC - N - I phase sequence was observed for both compounds. The temperature range of both SmC and nematic phases decreased with increasing the chain length. Dielectric spectroscopy is not only a good tool to investigate dielectric behavior and related optical properties with respect to external fields [44]; it is also a complementary technique to confirm the phase transitions detected by DSC. In addition, the sharp increase of $\varepsilon$ " in the vicinity of the transition from isotropic to nematic phase indicated the first order nature of this transition. Comparison of the electro-optical properties of compounds 8OBAF, 10OBAF and 12OBAF in Figs 10 and 11 revealed that both the threshold voltage and the birefringence decreased with increasing the chain length. A decreasing birefringence can be related by the reduction of the order parameter when the alkyl chain length increases. As lateral interactions are stronger for long alkyl chains, it might be expected that the order parameter would increase with respect to alkyl chain length. The opposite trend was observed. Several authors also found the same trends $[45,46]$. In qualitative accordance with our results, Pongali Sathya Prabu et al. [12] observed that the tilt angle increased and the field threshold of a SmC phase decreased with respect to chain length. Arakawa et al. [47] observed both increase and decrease of birefringence in a series of fluorinated dialkyl fluorinated diphenyl-diacetylene derivatives, showing the complexity of phenomena. The frustration of alkyl chain conformation caused by the lateral interactions between fluorinated aromatic parts may cause several contradictory packing effects. Organization of nOBAF molecules look being dominated by steric and polar lateral interactions between fluorinated aromatic parts. The low frequency relaxation occurring at $8 \mathrm{kHz}$ is consistent with the spontaneous polarization measurements and indicates to the presence of ferroelectric clusters.

To sum up the main disclosures, two new HBLC's exhibiting nematic and SmC phases have been synthesized and characterized. POM, DSC, XRD, dielectric and optical measurements provided a comprehensive view over the properties of such HBLC materials. The phase transitions detected by DSC and POM were confirmed by dielectric measurements. A cybotactic nematic phase was identified and studied using dielectric and electro-optic 
techniques. The influence of the alkoxy chain length on the optical properties of the nematic phase remains difficult to rationalize.

\section{Acknowledgement}

This work has received support by a French-Tunisian grant PICS from the Centre National de la Recherche Scientifique. 


\section{References}

[1] T. Kato, J.M.J. Fréchet, A new approach to mesophase stabilization through hydrogen bonding molecular interactions in binary mixtures, J. Am. Chem. Soc. 111 (1989) 8533-8534.

[2] G.M. Bennett, B. Jones, Mesomorphism and polymorphism of some $p$-alkoxybenzoic and $p$-alkoxycinnamic acids, J. Chem. Soc. (1939) 420-425.

[3] G.W. Gray, B. Jones, Mesomorphism and chemical constitution. Part I. The nalkoxynaphthoic acids, J. Chem. Soc. (1954) 683-686.

[4] G.W. Gray, B. Jones, Mesomorphism and chemical constitution. Part II. The trans- $p-n-$ alkoxycinnamic acids, J. Chem. Soc. (1954) 1467-1470.

[5] G.W. Gray, B. Jones, Influence of substituents on the mesomorphism of $p-n$ alkoxybenzoic and 6-n-alkoxy-2-naphthoic acids, Nature 170 (1952) 451-452.

[6] G.W. Gray, B. Jones, Mesomorphism and chemical constitution. Part III. The effect of halogen substitution on the mesomorphism of the 4-alkoxybenzoic acids, J. Chem. Soc. (1954) 2556-2562.

[7] G.A. Jeffrey, Carbohydrate liquid crystals, Acc. Chem. Res.19 (1986) 168-173.

[8] J. W. Goodby, Liquid crystal phases exhibited by some monosaccharides, Mol. Cryst. Liq. Cryst. 110 (1984) 205-219.

[9] J.W. Goodby, Phase Structures of Calamitic Liquid Crystals, in D. Demus, J.W. Goodby, G.W. Gray, H. W. Spiess, V. Vill, Eds, Handbook of Liquid Crystals, Vol 2A Low Molecular Weight Liquid Crystals I, Wiley-VCH (1998) 1-22.

[10] A. Blumtein, L. Patel, Molecular arrangement in mesophases of some $p$ - $n$ alkoxybenzoic acids, Mol. Cryst. Liq. Cryst. 48 (1978) 151-164.

[11] M. Petrov, A. Braslau, A.M. Levelut, G. Durand, Surface induced transitions in the nematic phase of 4-n-octyloxybenzoic acid, J. Phys. II France 2 (1992) 1159-1193.

[12] N. Pongali Sathya Prabu, M.L.N. Madhu Mohan, Characterization of a new smectic ordering in supramolecular hydrogen bonded liquid crystals by X-ray, optical and dielectric studies, J. Mol. Liq. 182 (2013) 79-90.

[13] M. Fouzai, R. Hamdi, S. Ghrab, T. Soltani, A. Ionescu, T. Othman, Properties of binary mixtures derived from hydrogen bonded liquid crystals, J. Mol. Liq. 249 (2018) 12791286.

[14] M.-J. Brienne, J. Galard, J.-M. Lehn, I. Stibor, Macroscopic expression of molecular recognition. Supramolecular liquid crystalline phases induced by association of 
complementary heterocyclic components, J. Chem. Soc., Chem. Commun. (1989) 18681870 .

[15] T. Kato, H. Adachi, A. Fujishima, J.M.J. Fréchet, Self-assembly of liquid crystalline complexes having angular structures through intermolecular hydrogen bonding, Chem. Lett. 21 (1992) 265-268.

[16] L.J. Yu, J.S. Pan, Mesophases induced by hydrogen bonds between non-mesogens. A di-proton acceptor and proton donors, Liq. Cryst. 14 (1993) 829-835.

[17] C.M. Paleos, D. Tsiourvas, S. Fillipakis, L. Fillipaki, Mesomorphic character of some long-chain 2,4,6-trichloro-1,3,5-triazine derivatives susceptible to facile functionalization, Mol. Cryst. Liq. Cryst. 242 (1994) 9-15.

[18] Z. Sideratou, C.M. Paleos, A. Skoulios, Liquid crystals from non-mesogenic anils induced through hydrogen bonding, Mol. Cryst. Liq. Cryst. 265 (1995) 19-26.

[19] T. Kato, M. Fukumasa, J.M.J. Fréchet, Supramolecular liquid-crystalline complexes exhibiting room-temperature mesophases and electrooptic effects. Hydrogen-bonded mesogens derived from alkylpyridines and benzoic acids, Chem. Mater. 7 (1995) 368372.

[20] Z. Sideratou, D. Tsiourvas, C.M. Paleos, A. Skoulios, Liquid crystalline behaviour of hydrogen bonded complexes of a non-mesogenic anil with $p$-n-alkoxybenzoic acids, Liq. Cryst. 22 (1997) 51-60.

[21] P. Swathi, P.A. Kumar, V. Pisipati, Crystal G phase induced through intermolecular hydrogen bonding IV: a study of crystallization kinetics, Liq. Cryst. 28 (2001) 11631169.

[22] Y. Arakawa, Y. Sasaki, H. Tsuji, Supramolecular hydrogen-bonded liquid crystals based on 4-n-alkylthiobenzoic acids and 4,4'-bipyridine: Their mesomorphic behavior with comparative study including alkyl and alkoxy counterparts, J. Mol. Liq. 280 (2019) $153-159$.

[23] U. Kumar, J.M.J. Fréchet, T. Kato, S. Ujiie, K. Timura, Induction of ferroelectricity in polymeric systems through hydrogen bonding, Angew. Chem. Int. Ed. Engl. 31 (1992) $1531-1533$.

[24] L.J. Yu, Hydrogen bond-induced ferroelectric liquid crystals, Liq. Cryst. 14 (1993) 1303-1309.

[25] Y. Tian, F. Su, Y. Zhao, X. Luo, X. Tang, X. Zhao, E. Zhou, Synthesis and variabletemperature FTIR study of five chiral liquid crystals induced by intermolecular hydrogen bonding, Liq. Cryst. 19 (1995) 743-748. 
[26] H. Kihara, T. Kato, T. Uryu, S. Ujiie, U. Kumar, J.M.J. Fréchet, D.W. Bruce, D.J. Price, Supramolecular ferroelectric liquid crystals. Hydrogen-bonded complexes between benzoic acids and chiral stilbazoles, Liq. Cryst. 21 (1996) 25-30.

[27] H. Grunert, R.A. Howie, A. Kaeding, C.T. Imrie, Supramolecular chiral liquid crystals. The liquid crystalline behaviour of mixtures of 4,4'-bipyridyl and 4-[(S)-(-)-2methylbutoxy]benzoic acid, J. Mater. Chem. 7 (1997) 211-214.

[28] E.B. Barmatov, A.Y. Bobrovsky, M.V. Barmatova, Induction of the cholesteric mesophase in hydrogen-bonded blends of polymers with a low molecular mass chiral dopant, Liq. Cryst. 26 (1999) 581-587.

[29] Y. Arakawa, Y. Sasaki, K. Igawa, H. Tsuji, Hydrogen bonding liquid crystalline benzoic acids with alkylthio groups: phase transition behavior and insights into the cybotactic nematic phase, New J. Chem. 41 (2017) 6514-6522.

[30] M. Fouzai, A. Guesmi, N. Ben Hamadi, T. Soltani, Fluoro-substitution in hydrogen bonding liquid crystal benzoic acid: dielectric, electro-optic and optical properties and inducing polar nematic phase, Liq. Cryst. (2019) in press, doi: 10.1080/02678292.2019.1679900.

[31] G. Si, Y. Zhao, E. Leong, Y.J. Liu, Liquid-crystal-enabled active plasmonics: a review. Materials 7 (2014) 1296-1317.

[32] A. Martínez-Felipe, A.G. Cook, M.J. Wallage, C.T. Imrie, Hydrogen bonding and liquid crystallinity of low molar mass and polymeric mesogens containing benzoic acids: a variable temperature Fourier transform infrared spectroscopic study, Phase Transitions 87 (2014) 1191-1210.

[33] J. Kumar, V. Prasad, Ferroelectric nematic and ferrielectric smectic mesophases in an achiral bent-core azo compound, J. Phys. Chem. B 122 (2018) 2998-3007.

[34] A.V.N. Ashok Kumar, M. Muniprasada, A.V.S.N. Krishna Murthy, P.V. Chalapathi, D.M. Potukuchi, Relaxation behavior of supra-molecular hydrogen-bonded liquid crystal phase structures: SA:11OBA, Mol. Cryst. Liq. Cryst. 624 (2016) 28-43.

[35] F. Haraguchi, K.-i. Inouie, N. Toshima, S. Kobayashi, K. Takatoh, Reduction of the threshold voltages of nematic liquid crystal electrooptical devices by doping inorganic nanoparticles, Jpn J. Appl. Phys. 46 (2007) L796-L797.

[36] R.-P. Pan, C.-F. Hsieh, C.-L. Pan, C.-Y. Chen, Temperature-dependent optical constants and birefringence of nematic liquid crystal $5 \mathrm{CB}$ in the terahertz frequency range, J. Appl. Phys. 103 (2008) 093523. 
[37] I. Haller, A. Huggins, H.R. Lilienthal, T.R. McGuire, Order-related properties of some nematic liquids, J. Phys. Chem. 77 (1973) 950-954.

[38] B. Żywucki, W. Kuczyński, G. Czechowski, Evaluation of the order parameter in nematic liquid crystals, Proc. SPIE Int. Soc. Opt. Eng. 2372 (1995) 151-156.

[39] B. Żywucki, W. Kuczyński, The orientational order in nematic liquid crystals from birefringence measurements, IEEE Trans. Dielec. Elec. Insul. 8 (2001) 512-515.

[40] W. Kuczyński, B. Żywucki, J. Małecki, Determination of orientational order parameter in various liquid-crystalline phases, Mol. Cryst. Liq. Cryst. 381 (2002) 1-19.

[41] C. Da Cruz, J.C. Rouillon, J.P. Marcerou, N. Isaert, H.T. Nguyen, Influence of the position and number of fluorine atoms and of the chiral moiety on a newly synthesized series with anticlinic properties, Liq. Cryst. 28 (2001) 1185-1192.

[42] H.F. Gleeson, S. Kaur, V. Görtz, A. Belaissaoui, S. Cowling, J.W. Goodby, The nematic phases of bent-core liquid crystals, Chem. Phys. Chem. 15 (2014) 1251-1260.

[43] M. Alaasar, C. Tschierske, Nematic phases driven by hydrogen-bonding in liquid crystalline nonsymmetric dimers, Liq. Cryst. 46 (2019) 124-130.

[44] Y. Boussoualem, M. Ismaili, J.M. Buisine, C. Binet, G. Joly, H.T. Nguyen, Dielectric and electro-optical properties of a photosensitive liquid crystal, Liq. Cryst. 36 (2009) 899-905.

[45] R. Dąbrowski, P. Kula, J. Herman, High birefringence liquid crystals, Crystals 3 (2013) 443-482.

[46] M. Tejaswi, P. Pardhasaradhi, B.T.P. Madhav, K. Pandian, P. Jayaprada, R.K.N.R. Manepalli, V.G.K.M. Pisipati, Optical properties of liquid crystalline alkoxy benzoic acids with dispersed citrate-capped gold nanoparticles, Z. Naturforschung A 74 (2019) 1001-1022.

[47] Y. Arakawa, S. Kang, J. Watanabe, G.-i. Konishi, Synthesis, phase-transition behaviors, and birefringence properties of fluorinated diphenyldiacetylene derivatives, Chem. Lett. 43 (2014) 1858-1860. 


\section{Table and Figures captions}

Table 1. Domains of existence $\left({ }^{\circ} \mathrm{C}\right)$ of the nematic and $\mathrm{SmC}$ phases for the 8OBAF, 10OBAF and 12OBAF compounds.

Figure 1. Chemical structure of nOBAF compounds ( $n=10: 10 \mathrm{OBAF}$ and $n=12: 12 \mathrm{OBAF})$.

Figure 2. IR spectra of 10OBAF (bottom) and 12OBAF (top).

Figure 3. DSC curves upon heating and cooling steps for 10OBAF (left) and 12OBAF (right). Arrows indicate the way of temperature variation (heating or cooling).

Figure 4. Polarized optical microscopy textures of 10OBAF. (a) Nematic phase and (b) SmC phase.

Figure 5. X-ray diffraction patterns of SmC, Nematic and Isotropic phases for 10OBAF (a, $\mathrm{c}, \mathrm{e})$ and $12 \mathrm{OBAF}(\mathrm{b}, \mathrm{d}, \mathrm{f})$.

Figure 6. Frequency dependence of $\varepsilon^{\prime}(\mathrm{a})$ and $\varepsilon^{\prime \prime}(\mathrm{b})$ for 10OBAF at selected temperatures.

Figure 7. Temperature dependence of $\varepsilon^{\prime \prime}$ at frequency $f=2 \mathrm{kHz}$ for $10 \mathrm{OBAF}$.

Figure 8. Temperature dependence of the relaxation frequency in the nematic phase of the 10OBAF. Symbols indicate the experimental data and the solid lines show the best fits using the Cole-Davidson distribution of relaxation times (Eq 1).

Figure 9. Temperature dependence of polarization in the nematic phase for 10OBAF

Figure 10. Temperature dependence of thresholds for 10OBAF and 12OBAF.

Figure 11. Temperature variation of birefringence $\Delta n$ for 10OBAF. 
Table 1

\begin{tabular}{ccccc}
\hline Compound & $\boldsymbol{T}_{\mathbf{m}}(\mathbf{C r y s t a l - S m F})$ & $\boldsymbol{T}(\mathbf{S m F}-\mathbf{S m C})$ & $\boldsymbol{T}(\mathbf{S m C}-\mathbf{N})$ & $\boldsymbol{T}$ (N-Iso) \\
\hline 8OBAF & 56 & 57.8 & 97 & 116 \\
& $\boldsymbol{T}_{\mathrm{m}}(\mathbf{C r y s t a l - S m C})$ & & $\boldsymbol{T}(\mathbf{S m C}-\mathbf{N})$ & $\boldsymbol{T}(\mathbf{N}-\mathbf{I s o})$ \\
10OBAF & 73 & & 94 & 113 \\
12OBAF & 87 & 98 & 109 \\
\hline
\end{tabular}

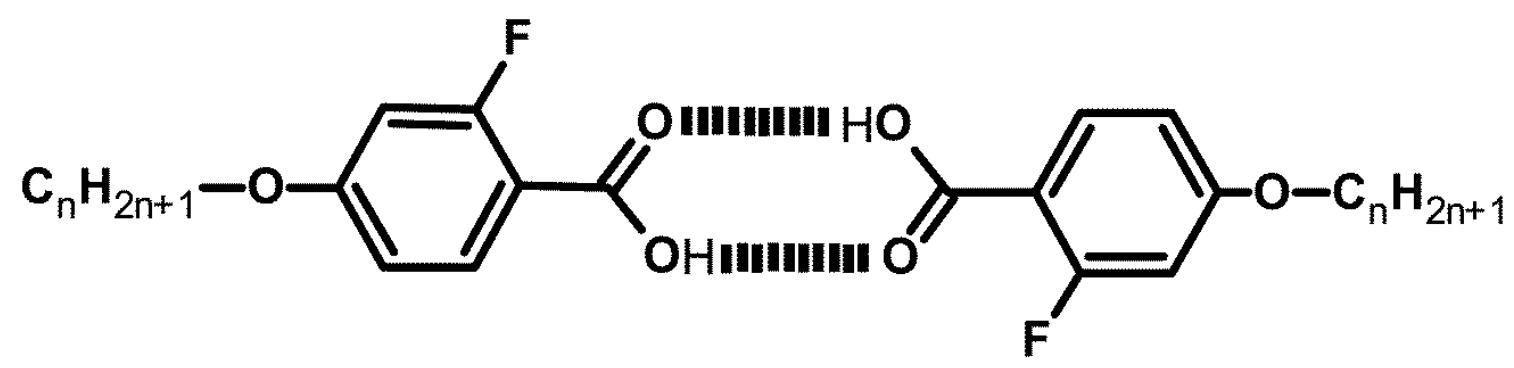

Figure 1

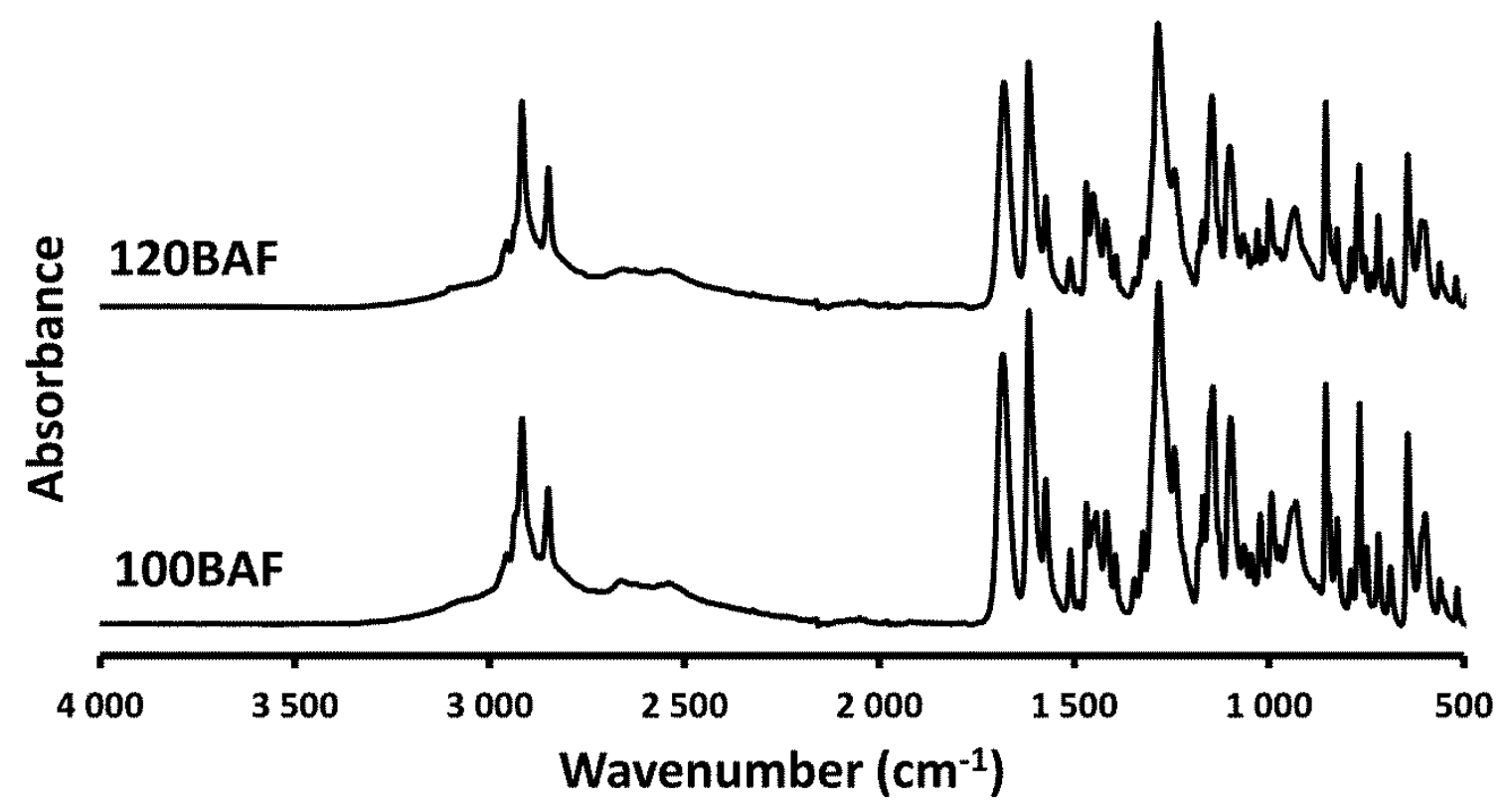

Figure 2 

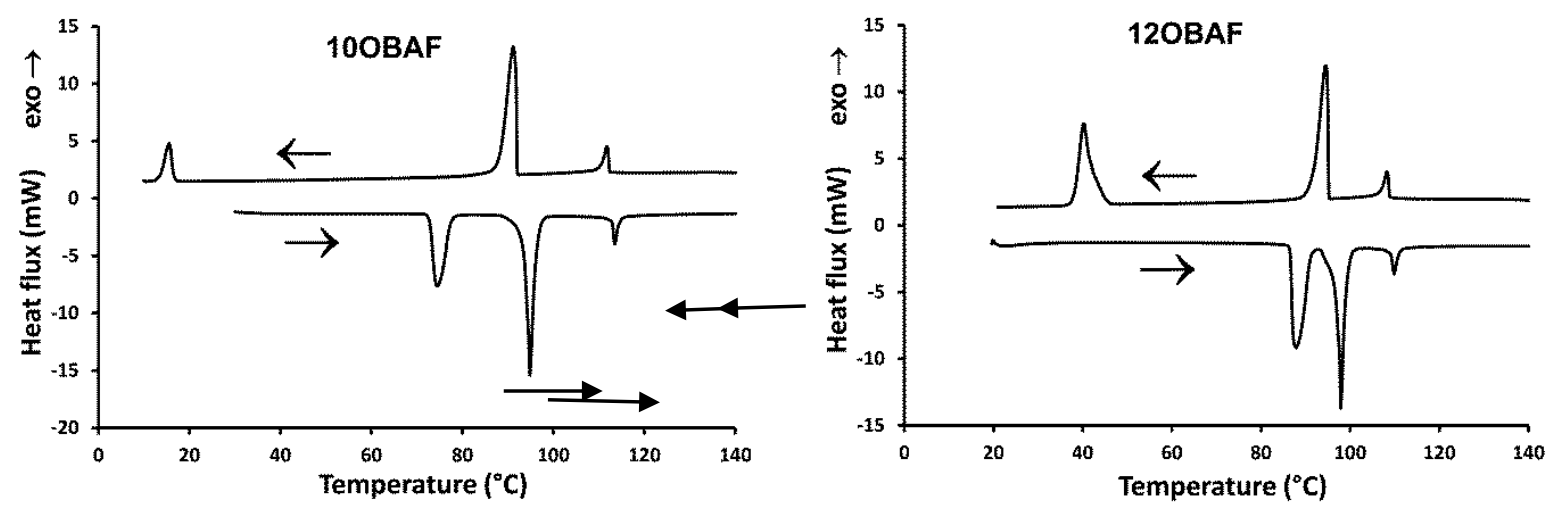

Figure 3
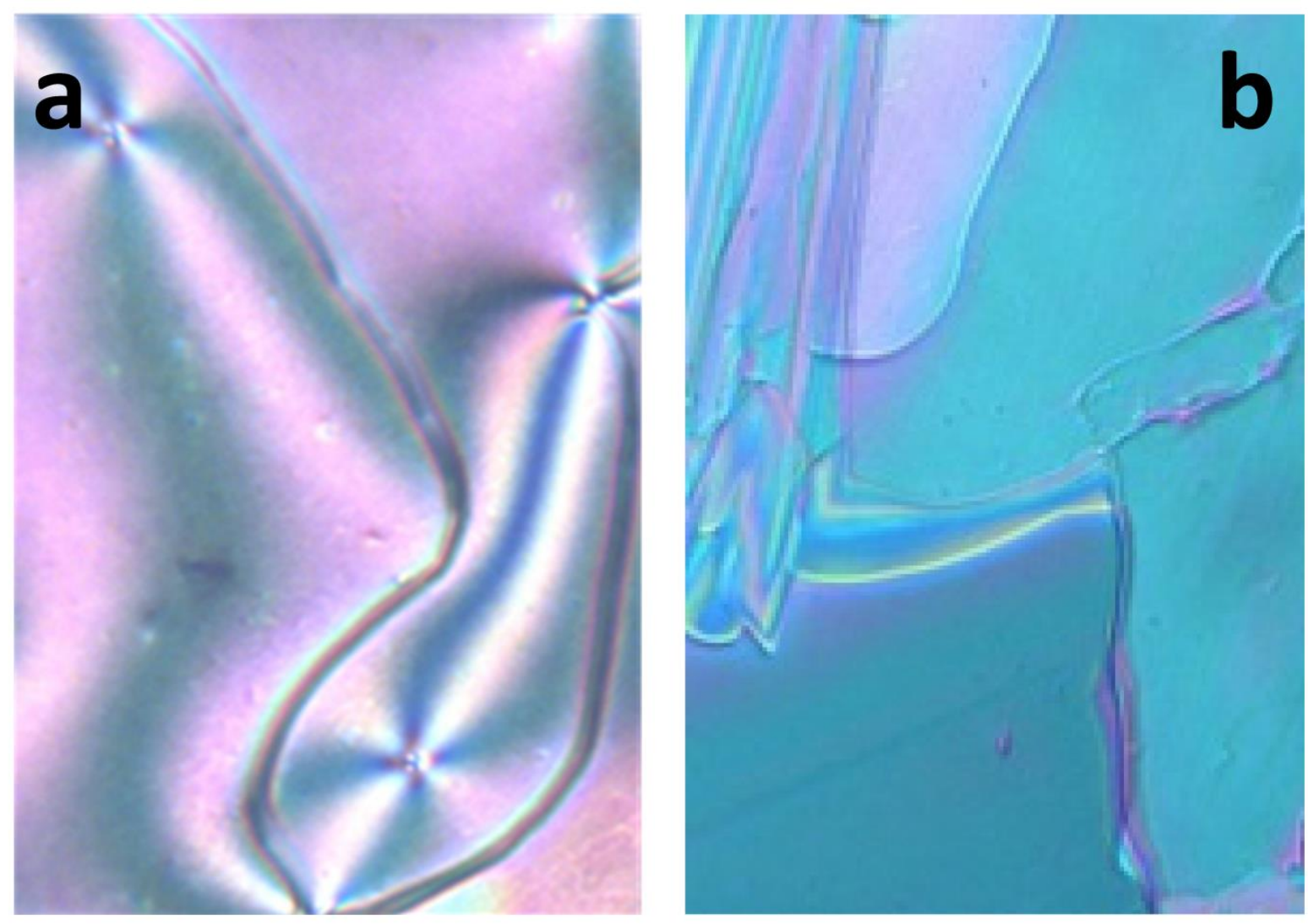

Figure 4 

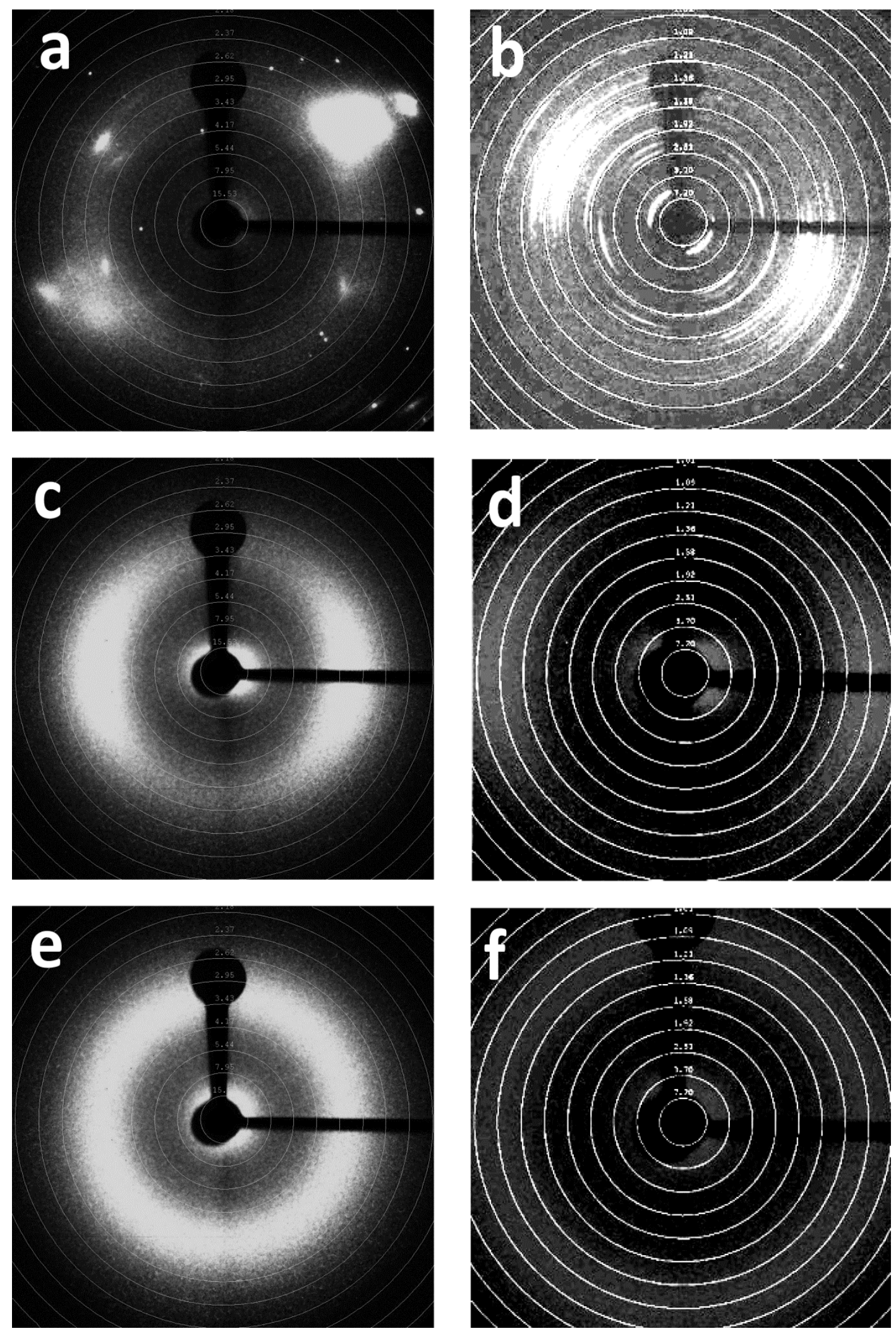

Figure 5 

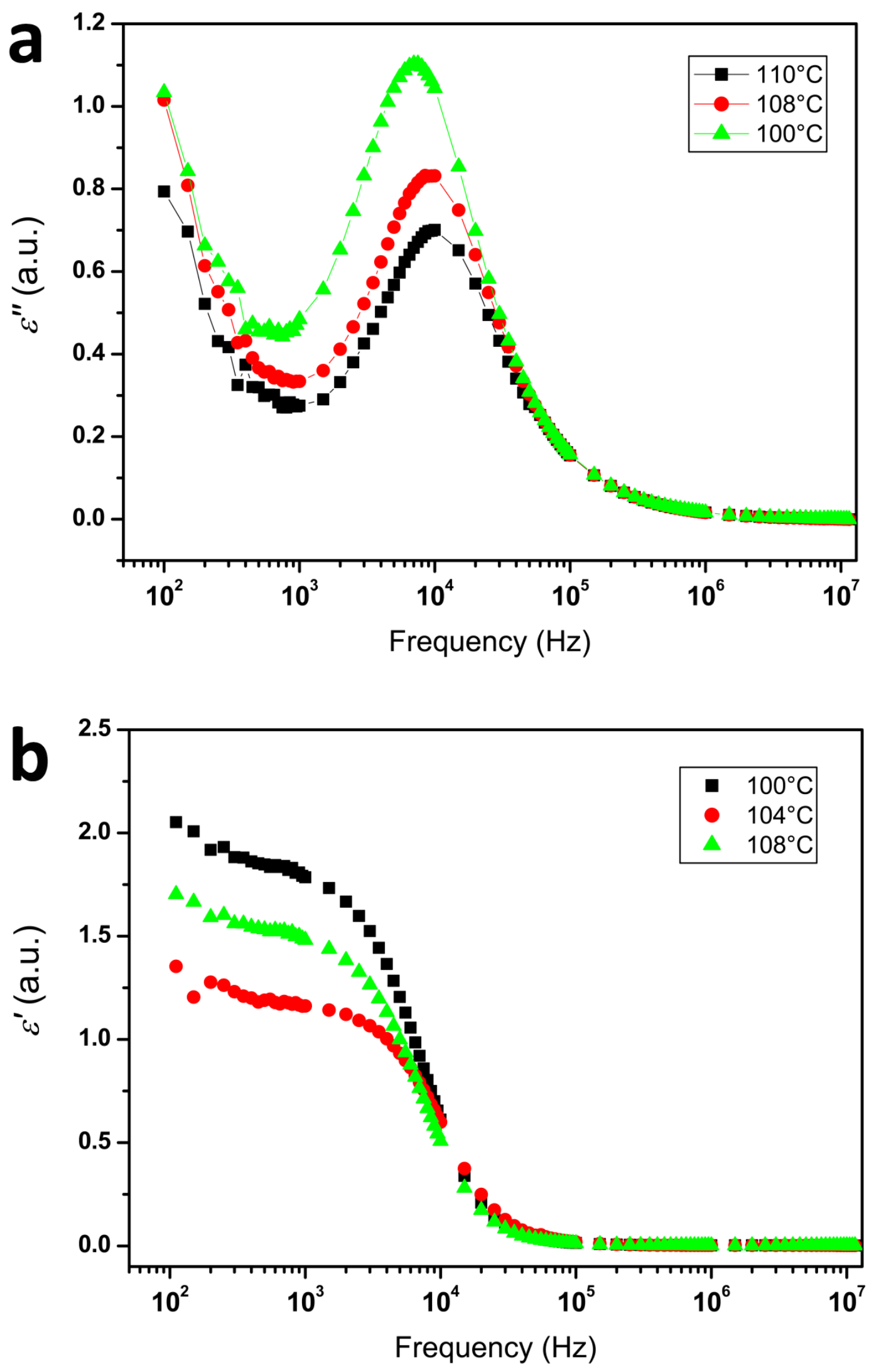

Figure 6 


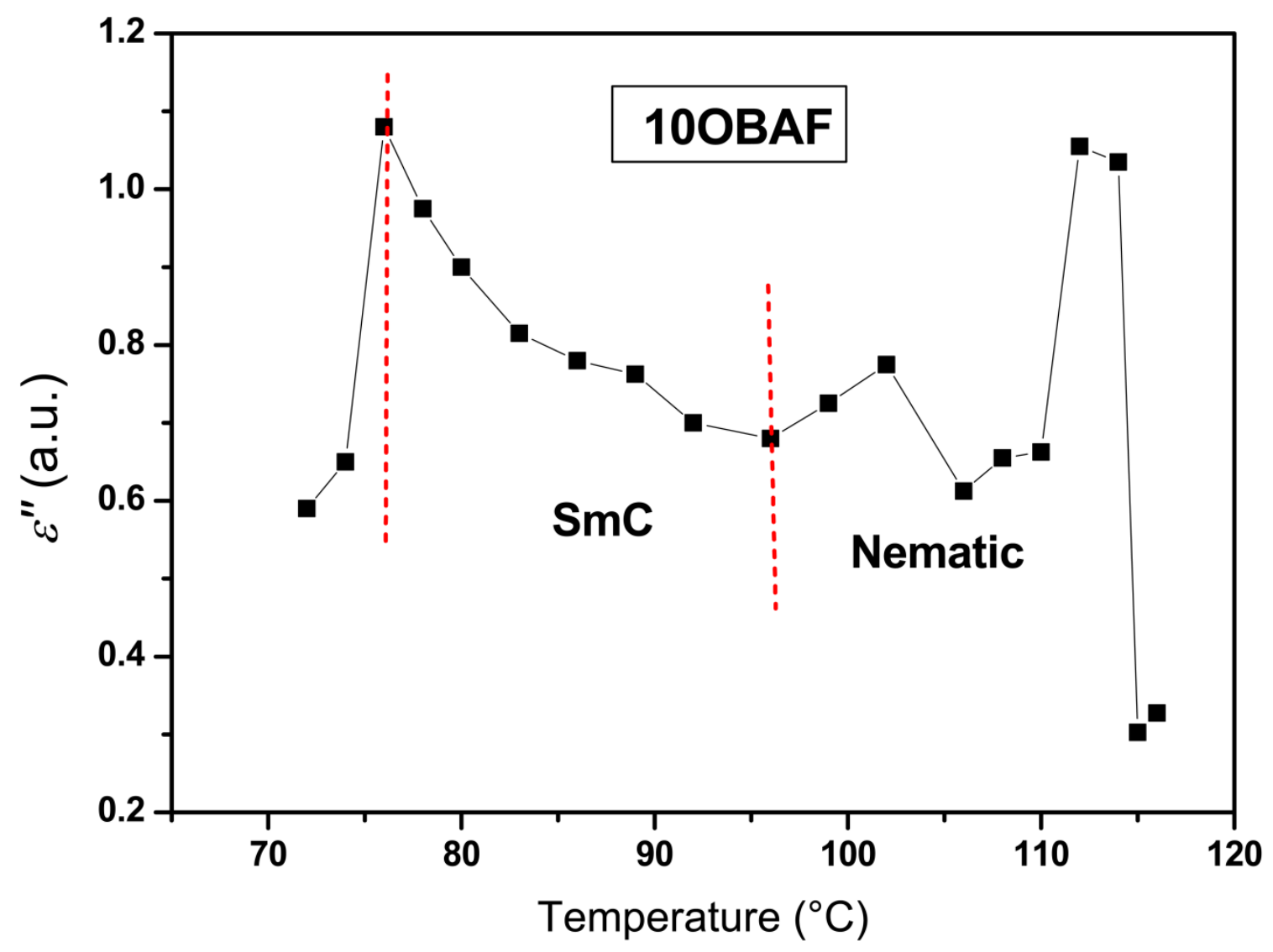

Figure 7 


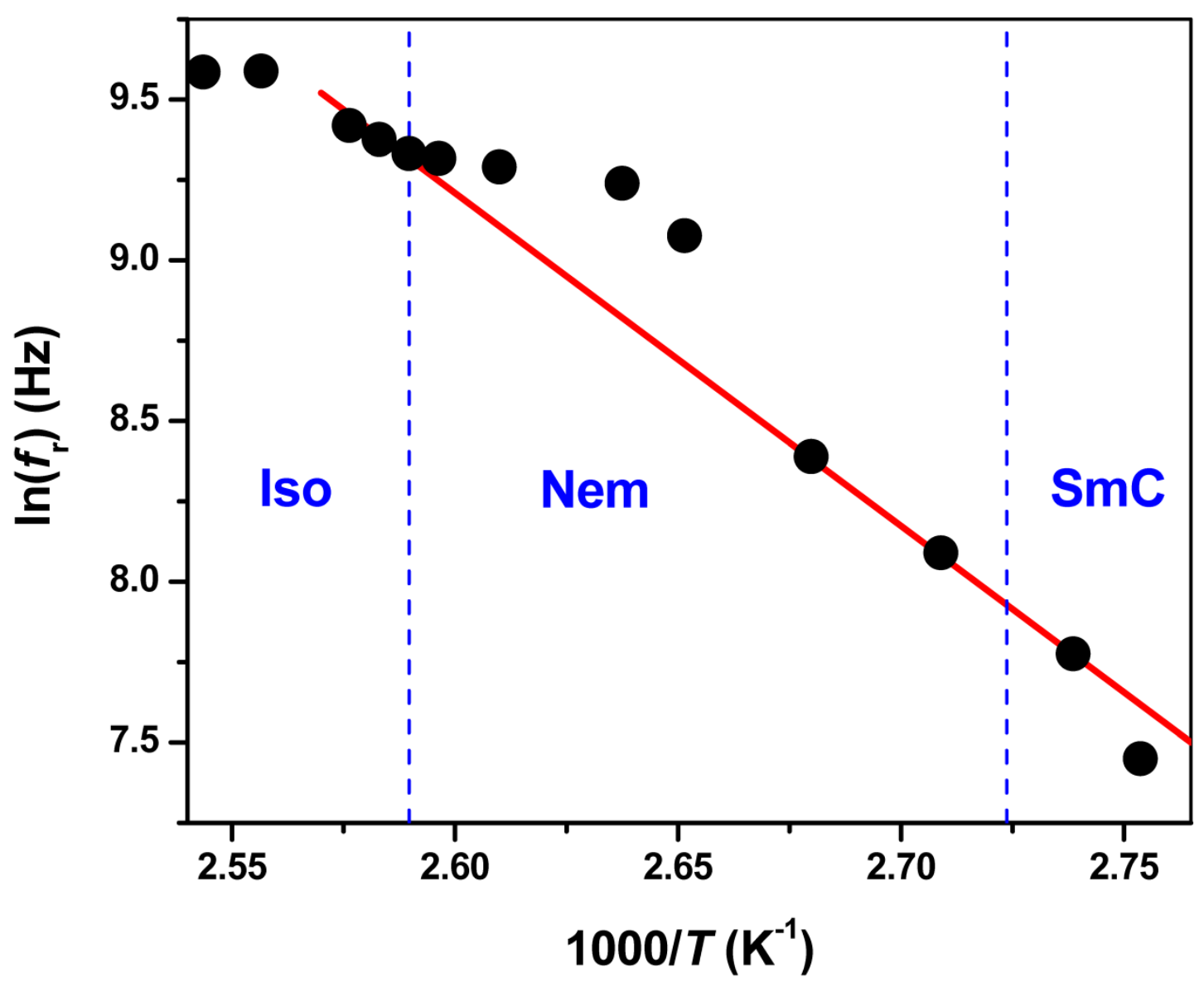

Figure 8 


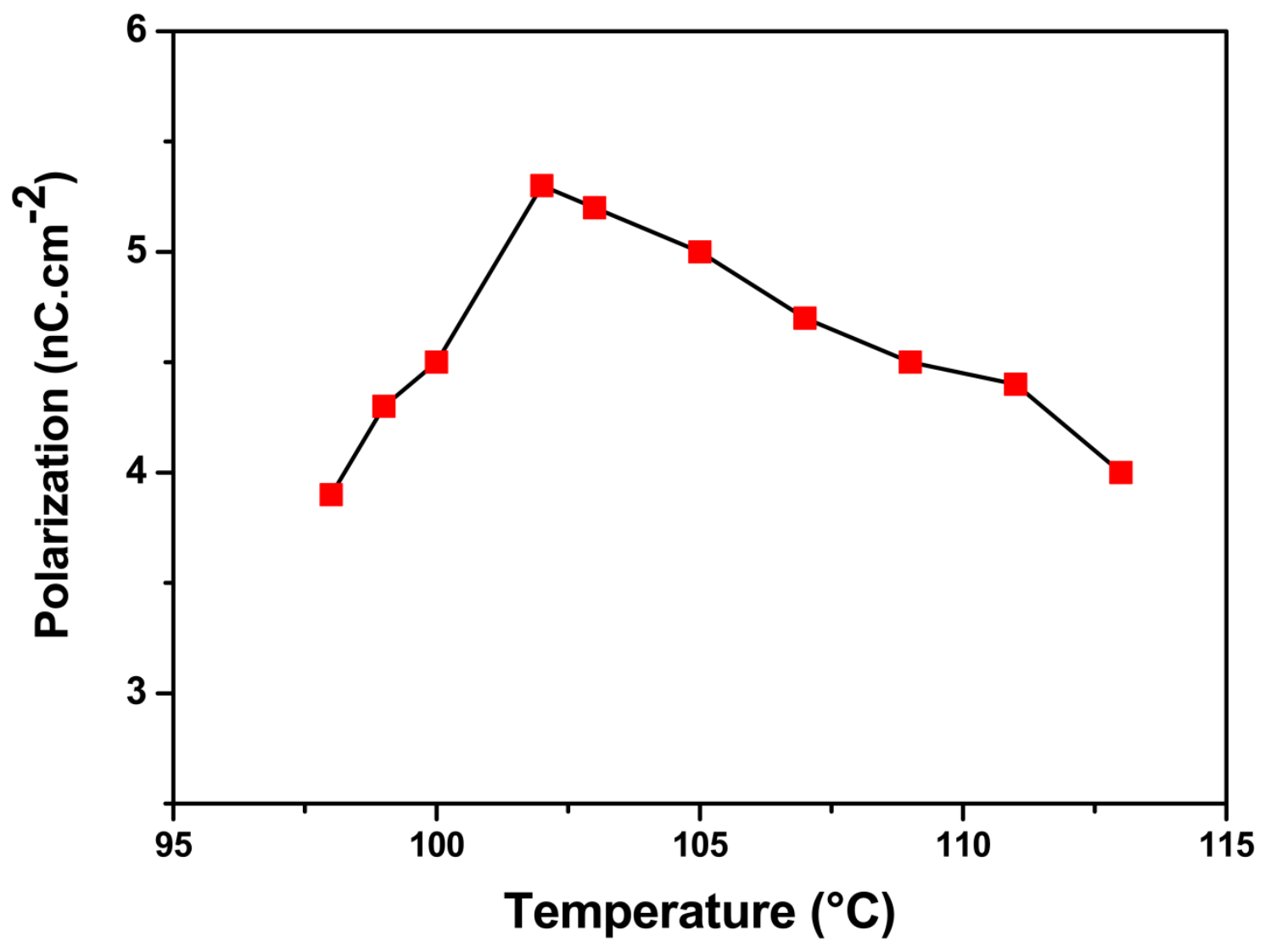

Figure 9 


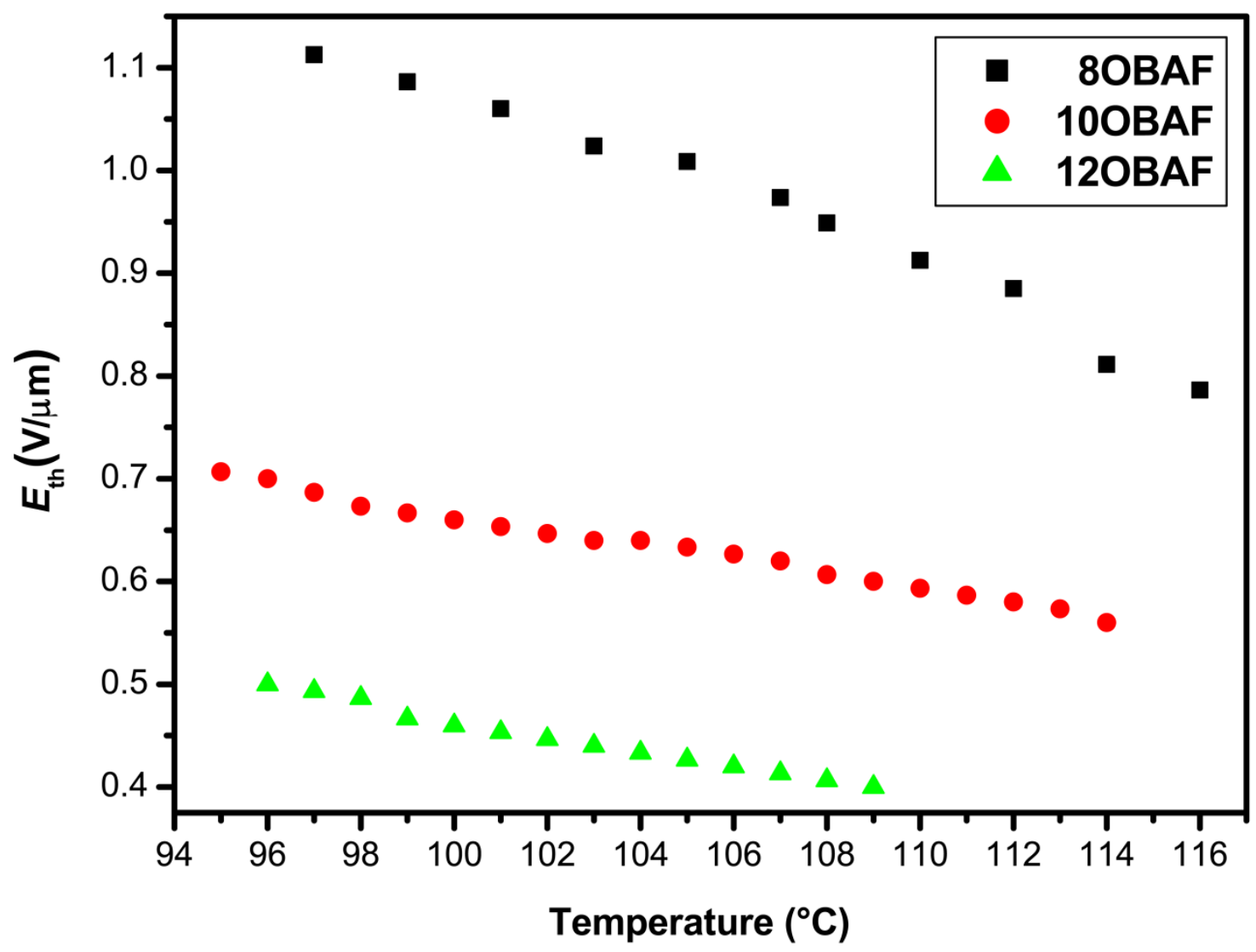

Figure 10 


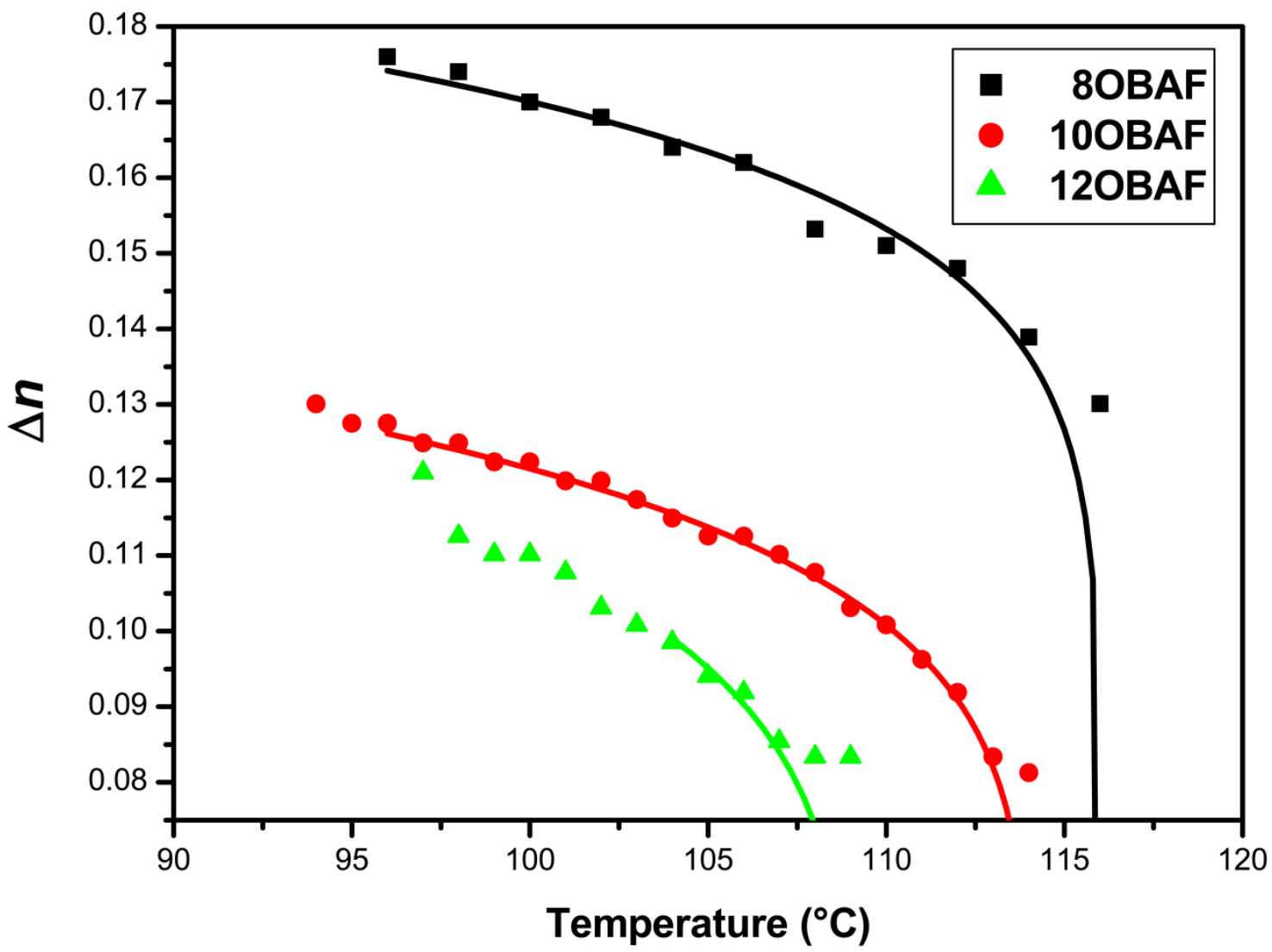

Figure 11 